\title{
The Ability of Scientific Reasoning and Mastery of Physics Concept of State Senior High School Students in Palembang City
}

\author{
Suhardi Effendy ${ }^{1}$, Hartono $^{2}$, Ian Yuliant ${ }^{3 i}$ \\ ${ }^{1,2,3}$ Graduate School, Universitas Negeri Semarang, Semarang, Indonesia \\ ${ }^{1}$ Coresponding email: ardifendy@gmail.com
}

\begin{abstract}
Reasoning is an indispensable ability of learners in physics learning as it is related to the learning outcomes achieved. This study aims to obtain a picture of scientific reasoning in 231 high school students in Palembang City in academic year 2017/2018. The type of this research is descriptive research with survey method. The ability of scientific reasoning and mastery of the physics concepts of students was obtained through written test in the form of multiple choice reasons. Problems used in the study contained 18 items with details of 12 questions about scientific reasoning and 6 questions about mastery of physics concepts. The result of the research shows the scientific reasoning ability of high school students was in the low category and the mastery of physics concept of students remained in the medium category.
\end{abstract}

Key words: scientific reasoning, mastery of physics concepts, physics learning

\section{Introduction}

Curriculum changes that occurred in mid2014 known as the revised 2013 curriculum allows changes in the learning process. Current education should not only use learning that leads students to memorize, but also integrate reasoning skills in their activities (Oktafianti, 2015). The inclusion of reasoning aspects in the standard of learning process is very important because reasoning is an abstract thinking activity (Wijaya, 2016). Good reasoning can support the understanding of good concepts in physics content (Purwati, Supriyono, and Siti, 2016).

The ability of reasoning and the maturation of a mature concept is absolutely necessary in studying physics that links more than one concept (Nurhayati, Yuliati, and Mufti, 2016; Muchsin and Khumaedi, 2017). Many students are unsure of their ability to study physics (Huber et al., 2015). Solutions such problems include teachers should be able to optimally utilize the facilities that have been provided at school (Usmeldi, 2016). The students' success in understanding the concept is highly dependent on the teacher's skills as a facilitator in designing learning scenarios and building thinking skills, studying concepts with the logic, and scientific attitudes of learners (Shofiyah, Supardi, and Jatmiko, 2013). Improved reasoning ability can significantly influence the learning process undertaken by students (Steinberg and Sebastian, 2013). A teacher needs to know the ability of reasoning and mastery of student concepts (Abdurrahman, Efendi, and Wijaya, 2013).

Reasoning is a general concept which refers to one thought process to arrive at a conclusion as a new statement of some other known statement. Copi (1978) calls reasoning a specific way of thinking to draw conclusions from the premises. Reasoning has an important role in problem solving. Reasoning is a conscious, systematically directed thinking activity that aims to produce valid and correct conclusions. This includes scientific reasoning. This reasoning is a synthesis between empirical inductive reasoning and rational inductive reasoning, and is logical and analytical (Slamet, 2008). The logical nature shows that reasoning is done according to certain logical patterns, whereas the nature of analysis shows that reasoning is based on steps as a consequence of the use of that pattern of thought.

Scientific reasoning has two reasoning patterns, namely the pattern of concrete reasoning and formal reasoning patterns. The pattern of concrete reasoning is class inclusion, conservation, serial ordering, and reversibility. While formal reasoning patterns include theoretical reasoning, combinatorial reasoning, functionality and proportional reasoning, control variables, and probabilistic, and correlational reasoning (Karplus, 1977). In the scientific reasoning test instrument (test of scientific reasoning) developed by Lawson the reasoning pattern is grouped into three levels of scientific reasoning namely concrete, 
transitional, and formal reasoning operations (Kemendiknas, 2013).

The ability of reasoning is not a static ability that is brought at birth. The development of reasoning ability is influenced by many factors. Likewise with scientific reasoning. The science approach and method of teaching used by teachers is one of the factors that can influence the development of scientific reasoning. Scientific thinking and reasoning skills can be trained through physics learning that is conducted using a scientific approach (Agustin, Yulianti, and Zulaikah, 2016). In the process of learning based on a scientific approach, the (affective) sphere of dominance transforms the substantive substance or teaching material so that learners "know why." The skill area (psychomotor) takes the transformation of substance or teaching material to make the learners "know how". The realm of knowledge (cognitive) takes the transformation of substantive substance or teaching material to make the learner "know what." The end result is the improvement and balance between the ability to be a good human (soft skills) and human being with the skills and knowledge to live properly (hard skills ) of learners that includes aspects of attitude, skills, and knowledge competencies.

The 2013 curriculum emphasizes the modern pedagogic dimension of learning, using a scientific approach. The scientific appoach in such learning involves observing, asking, trying, processing, presenting, summarizing and creating for all subjects. For certain subjects, materials, or situations, it is very likely that this scientific approach is not always aptly applied procedurally. In these circumstances, the learning process must, of course, still apply scientific values or traits and avoid non-scientific values or traits.

The material of Momentum and Impulse is one of the materials studied in class X. This material has not previously been discussed in junior high school, so students do not have a basic concept of the material. The concept of this material is a concept that is abstract and theoretical. There are still many students experiencing misconceptions so students have difficulty in solving Momentum and Impulse problems (Agustin, Yulianti, and Zulaikah, 2016; Anggraeni and Suliyanah, 2017). This should be considered by educators in conveying the basic concepts of Momentum and Impulse materials, since the previous students have never received this material at the junior level, so the correct understanding of the concept must absolutely be given to a student teacher.

Palembang is one of the cities in South Sumatra. The city of Palembang has 161 high schools, consisting of 31 SMA Negeri, and 130 private SMA. All state senior high schools in Palembang have implemented Curriculum 2013. In addition, Ministry of Education and Culture stated that the Human Development Index (IPM) which one aspect of its assessment is the quality of education shows that the ranking of provinces on the island of Sumatra always under Java. Based on the above description, this study aims to describe the ability of scientific reasoning and mastery of physics concepts in public high school students in the city of Palembang on the material Momentum and Impulse. In this study students' scientific reasoning abilities are explored using scientifically applied scientific reasoning tests of Classroom Test of Scientific Reasoning instruments (Lawson, 2000). While the ability of mastering the concept of students in exploration with multiple choice questions reasoned by using 6 items.

\section{Research methods}

Descriptive research with survey method aims to obtain a picture of scientific reasoning (scientific reasoning) and mastery of physics concepts in high school students in the city of Palembang in the academic year 2017/2018. Research subjects amounted to 231 students. Scientific reasoning data was obtained through a written test using a scientific reasoning instrument adopted from a test instrument developed by Lawson [18] that is classroom test of scientific reasoning (CTSR). As for the mastery of the concept of physics, students are given a matter of double-choice beralasan with reference to Bloom's taxonomy.

The test instrument used in the form of multiple choice is based on 12 items. Each item has a choice of answers and a choice of reasons for choosing the answer. Each question has a score of 1 if the answer and the reason chosen are correct. If the answer or reason is wrong, or both are wrong then the score is 0 . The maximum score of 12 is obtained if all items are answered correctly and the reason chosen is also correct. While 
the concept mastery test instrument consists of 6 multiple choice questions reasoned.

The scientific reasoning indicator used in the scientific reasoning test instrument in this study is shown in Table 1 . The test data obtained is then analyzed to determine the grouping of students' scientific reasoning level. There will also be an analysis of the achievement of each scientific reasoning indicator used. The students' scientific reasoning level is determined based on the test scores obtained. A score of 0-4 shows the level of concrete operational reasoning, the 5-8 score shows reasoning at the transitional level, the score 9-12 indicates the level of formal reasoning [18]. While the concept mastery indicator is shown in Table 2.

Table 1. Scientific Reasoning Indicators

\begin{tabular}{cl}
\hline $\begin{array}{c}\text { Question } \\
\text { Number }\end{array}$ & \multicolumn{1}{c}{ Question Indicators } \\
\hline 1 & Conservation of \\
2 & weight \\
3 & Conservation of displaced volume \\
4 & Proportional thinking \\
5 & Advanced proportional thinking \\
6 & Identification and control of variables \\
7 & Identification and control of variables and probabilistic thinking \\
8 & Advanced identification and control of variables and probabilistic \\
9 & thinking \\
10 & Probabilistic thinking \\
11 & Advanced probabilistic thinking \\
12 & Correctional thinking, includes proportions and probability \\
\hline
\end{tabular}

Table 2. Concept Mastery Indicators

\begin{tabular}{|c|c|c|}
\hline $\begin{array}{l}\text { Cognitive } \\
\text { Level }\end{array}$ & $\begin{array}{l}\text { Aspect of Mastery } \\
\text { Concepts }\end{array}$ & Indicator \\
\hline $\mathrm{C} 1$ & Remember & $\begin{array}{l}\text { a. Recognize } \\
\text { b. Recalling }\end{array}$ \\
\hline $\mathrm{C} 2$ & Understand & $\begin{array}{l}\text { a. Interpret } \\
\text { b. Exemplify } \\
\text { c. Classify } \\
\text { d. Summarize } \\
\text { e. Conclude } \\
\text { f. Comparing } \\
\text { g. Explain }\end{array}$ \\
\hline $\mathrm{C} 3$ & Apply & $\begin{array}{l}\text { a. Execute } \\
\text { b. Implementing }\end{array}$ \\
\hline $\mathrm{C} 4$ & Analyze & $\begin{array}{l}\text { a. Distinguish } \\
\text { b. Organize } \\
\text { c. Attribute }\end{array}$ \\
\hline $\mathrm{C} 5$ & Evaluate & $\begin{array}{l}\text { a. Check } \\
\text { b. Criticize }\end{array}$ \\
\hline C6 & Create & $\begin{array}{l}\text { a. Formulate } \\
\text { b. Plan } \\
\text { a. Produce }\end{array}$ \\
\hline
\end{tabular}




\section{Results and Discussion}

The test questions have been converted into Bahasa Indonesia and have passed the test of validity and reliability. The test questions consisted of 12 items representing 12 indicators of scientific reasoning as shown in Table 1. The scoring system and the determination of the level of scientific reasoning refer to the scoring system guidelines advanced by Lawson (2000). The results of data analysis of students' scientific reasoning level is displayed in the following table.

Table 3. Scientific reasoning level of students

\begin{tabular}{cc}
\hline Reasoning Level & $\begin{array}{c}\text { The number of } \\
\text { students }(\%)\end{array}$ \\
\hline Concrete Operations & 33.11 \\
Transitional & 30.41 \\
Formal Operations & 27.81 \\
\hline
\end{tabular}

Based on Table 3 it is seen that the number of students with scientific reasoning at the concrete Operational level occupies the most positions, while the formal operational level is in the least order. This result conflicts with the theory of cognitive development which states that children aged 11 and over should have had scientific reasoning ability at formal operational level (Piaget, 1964). Table 3 shows that in general the students are able to correctly answer the questions with indicators 1 to 4 (heavy conservation, volume conservation, proportional thinking, and advanced proportional thinking), then tend to decrease from indicator 5 to 12 . The smallest indicator achievement in indicator 11 is on the deductive hypothetical reasoning indicator. Declining trend indicator indicator indicates that the problem is arranged with increasing difficulty level. This means that scientific reasoning indicators are arranged in stages that represent reasoning from concrete operational levels to formal operations. Only students with formal operational reasoning levels are able to correctly answer the questions with indicators 9 through 12. Scores of scientific reasoning tests are further analyzed for each level of students' scientific reasoning. The description of the achievement of each scientific reasoning indicator is shown in Figure 1.

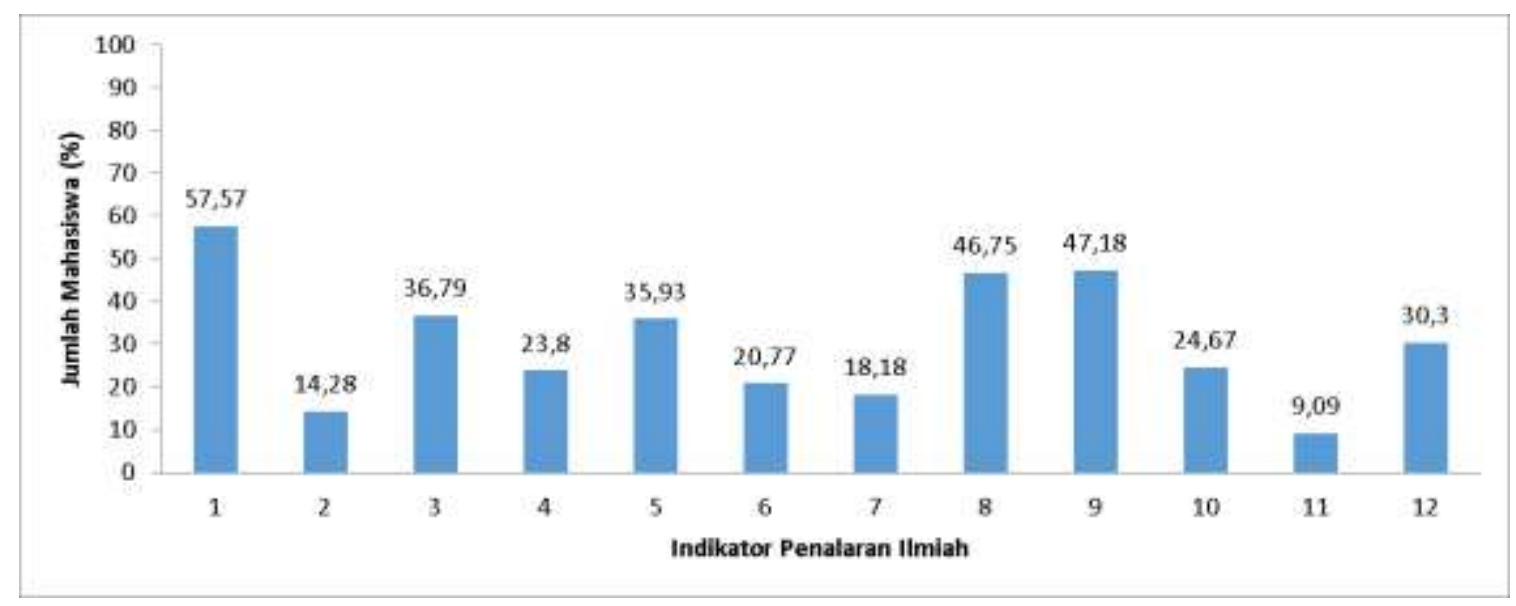

Figure 1. Graph of achievement per indicator on scientific reasoning ability

Based on Figure 1, it can be seen that in the indicator 1 there are $57.57 \%$ of students who can answer the problem correctly and the reasons. For the lowest score found in indicator 11, because of 231 students only $9.09 \%$ of people who can answer correctly and the reasons. This happens because in learning teachers do not familiarize students to reason scientifically. Most teachers are only oriented to the students' ability to solve math problems. Students are only accustomed to answering questions based on their memorization alone rather than by reasoning. Overall, from 231
SMA Negeri in the city of Palembang in the subject of research, their scientific reasoning ability is at $20.44 \%$ and fall into the low category.

The ability to reason reasoning is not a static ability brought about by birth. Likewise the ability of scientific reasoning. It develops according to the factors that influence it. One of the factors that can influence the development of students' scientific reasoning is the approach and method of science learning used by the teacher. The maximum competence of students' scientific reasoning is 
possible because the science learning received by students from elementary school to junior high school has not maximally involved them in the scientific process, but more focused on the knowledge aspect. Physical learning done by teachers has not been maximally oriented towards scientific approaches and methods. Physical learning that should be able to encourage thinking and scientific reasoning (physics) is not working properly.

The low ability of students 'scientific reasoning will also affect the mastery of students' concepts. Based on the results of research, the mastery of the physics concept of high school students in Palembang city can be seen in Table 4.

Table 4. Ability to master physics concept

\begin{tabular}{cc}
\hline $\begin{array}{c}\text { Cognitive } \\
\text { Level }\end{array}$ & $\begin{array}{c}\text { The number of } \\
\text { students }(\%)\end{array}$ \\
\hline C1 & 87.01 \\
C2 & 43.72 \\
C3 & 66.23 \\
C4 & 41.99 \\
C5 & 58 \\
C6 & 65.36 \\
\hline
\end{tabular}

From Table 4 we see that the mastery of student concepts on the $\mathrm{C} 1$ level cognitive ranks highest with the percentage of $87.01 \%$ and included in the timggi category. At this level students are faced with the problem of memorizing and most students are able to answer correctly. While the lowest mastery of the concept is at the level of cognitive C4 of $41.99 \%$ and included in the category of being. At this level students are faced with the problem of analyzing to conclude something and only a small percentage of students are able to answer the problem correctly. If it is associated with reasoning ability, it is obvious that students who have good scientific reasoning ability will master the concept well too. This explains that the ability of scientific reasoning and mature conceptualization is absolutely necessary in studying physics that links more than one concept.

Overall ability mastery of student concept is at number $60,38 \%$ and included in medium category. Students can answer precisely the questions that are at the $\mathrm{C} 1$ cognitive level that are remembering, the $\mathrm{C} 2$ which is the nature of understanding and the $\mathrm{C} 3$ which is its application. While in the questions that are cognitive level $\mathrm{C} 4$ that are analyzing, C5 which is evaluating and C6 create, students tend to be in trouble and have difficulty in answering the problem. This happens because in the learning process students are rarely confronted with something contextual related to the material being studied. Teachers are oriented only on students' mathematical abilities, finally when students are faced with problems that require analytical skills, evaluate and create them difficult to solve the problem.

To solve the problem of low scientific reasoning ability and mastery of physics concept in public high school students in Palembang city, it is expected that teachers will start to use the results of the research of educational practitioners as a reference for preparing lesson plans that will be carried out. In addition, teachers should start using some of the models and methods that have been developed by educational practitioners to improve scientific reasoning and mastery of student concepts.

\section{Conclusions}

Based on the results and discussion above, it can be concluded that scientific reasoning of public senior high school students in Palembang city for academic year 2017/2018 was at the level of concrete operational reasoning (33.11\%), transitional (30.41\%), and formal operational (27.81\%). Overall students' scientific reasoning ability was $30.44 \%$ and included into the low category. Mastery of physics concept of student on momentum and impulse material based on cognitive level $\mathrm{C} 1$ was $87.01 \%$; C2 was $43.72 \%$; C3 was $66.23 \%$, C4 was $41.99 \%$; C5 was $58 \%$ and C6 was $65.36 \%$. Overall mastery of the concept of physics of state senior high school students in the city of Palembang reached $60.38 \%$, and it is included in the category of being.

\section{Reffrences}

Abdurrahman, D., Efendi, R and Wijaya, A.F.C. (2013). Level of Reasoning Profile and Improved Mastery of High School Student Concept in Physics-Based Learning Task Exercise Peer Instruction. Jurnal Wahana Pendidikan Physics. 1: 84-91.

Agustin, D. K., Yulianti, L and Zulaikah, S. (2016). Mistakes of High School Students in Solving the Impulse-Momentum 
Problem. Proceeding of National Seminar of Science Education Postgraduate of University of Malang. 1. 174-183.

Anggraeni, D. M. and Suliyanah. (2017). Diagnosis of Student Misconception on Momentum, Impulse, and Collision Material Using Three-Tier Diagnostic Test. Journal of Physical Education Innovation (JIPF), 6 (03): 271-274.

Copi, I. M. (1978). Introduction to Logic. New York: Mcmillan.

Huber, A. S., J. Hausler, V. Jurik, dan T. Seidel. (2015). Self-underestimating students in physics instruction: Development over a school year and its connection to internal learning processes. Learning and Individual Differences, 43: 83-91.

Karplus, R. (1977). Science teaching and the development of reasoning. Journal of Research in Science Teaching, Vol. 14(2): 169-175.

Kemendiknas. (2013). Concept of Scientific Approach. Teacher Training Module in the Framework of Implementation of Curriculum 2013.

Lawson, A.E. (2000). Development and validation of the classroom test of formal reasoning: Revised Edition. Arizona State University.

Muchsin and Khumaedi. (2017). Analysis of the skills of prospective teachers in explaining the concept of using analogies in Physics learning. Physics Communication, 1 (1): 23-33.

Nurhayati, L.Yuliati and N. Mufti. (2016). Pattern of Scientific Reasoning and Ability to Solve Physical Synthesis Problems. Journal of Education: Theory, Research and Development, 1 (8): 15941597.

Oktafianti, E. (2015). Implementation of scientific approach based learning in 1st B grader of Pujokusuman 1 Yogyakarta.
Journal of Elementary School Teacher Education. 9 (IV).

Purwati, S., Supriyono, K. H and Siti, Z. (2016). Correlation between Scientific Reasoning and Student Concept Understanding on Matter of Business and Energy. Proceedings of National Seminar on Science Education Postgraduate State University of Malang, Vol. 1: 479-483.

Piaget, J. (1964). Cognitive development in children : development and learning. Journal of Research in Sciences Teaching, 2. 176-186.

Shofiyah, N., Supardi, Z.A.I and Jatmiko, B. (2013). Developing Scientific Reasoning of Students through 5E Learning Model at X-Grade Students of SMAN 15 Surabaya. Jurnal Pendidikan IPA Indonesia, 2(1): 83-87.

Slamet, Sy.Y. (2008). Alternative Development Of Thinking Ability of Thought And Creative In Learning Indonesian. Paper at Open Senate Session on Inauguration of Indonesian Professor. Sebelas Maret University.

Steinberg, R and Sebastian, C. (2013). Understanding and Affecting Science Teacher Candidates' Scientific Reasoning in Introductory Astrophysics. Physical Review Special Topics-Physics Education Research, 9 (2): 1-10, in The American Physical Society.

Usmeldi. (2016). Development of ResearchBased Physics Learning Model With Scientific Approach To Develop Scientific Processing Skills of Students. Jurnal Pendidikan IPA Indonesia, 5 (1): 134-139.

Wijaya, H. (2016). Improving the Ability of Reasoning and Student Representation Through Learning Open Ended Approach. Journal of Primary School Teacher Education, 2 (1): 12-29. 